\title{
Menos estado, menos polícia, mais segurança privada: uma análise da estrutura da política de segurança no governo FHC e seus impactos em Pernambuco (1995-2000)
}

\author{
Less state, less police, more private security: an analysis of the structure of the security \\ policy during the FHC government and its impacts in Pernambuco (1995-2000)
}

\author{
Carlos Luiz de Santana \\ Graduado em Licenciatura Plena em História, \\ Universidade Federal Rural de Pernambuco (UFRPE), \\ Recife, PE, Brasil. Especialização em Ciência Política \\ Fundação de Ensino Superior de Olinda (FUNESO), \\ Olinda, PE, Brasil \\ carlos-luiz@ig.com.br
}

\section{Erinaldo Ferreira do Carmo}

Doutor em Ciência Política e Professor, Universidade Federal de Pernambuco - UFPE, Recife, PE, Brasil erinaldocarmo@gmail.com
Resumo: Os paradigas de segurança pública derivam dos tipos das políticas associadas aos modelos de estado. No Brasil na década de 1990 estava na ordem do dia a reforma do estado, para estado gerencial, ou mínimo. Caracterizou-se pela diminuição da atuação do estado como fornecedor de serviços públicos, cedendo lugar às iniciativas privadas e às forças do mercado. Não foi diferente com a segurança pública. Tentou-se tornar os setores policiais militares mais eficientes através de reorganização, reordenação e aparelhagem técnicas destas instituições. Mas, teve como consequência a estagnação no fornecimento de agentes públicos, de segurança, para as vias e espaços públicos, comparada ao aumento progressivo da população. Ao lado desta estagnação viu-se o crescimento do setor privado de segurança como fornecedor destes serviços, porém para aqueles que poderiam pagar. Para os que não podiam sobrou a segurança privada clandestina, nos bairros pobres. Este molde de política de segurança atingiu Pernambuco, no período, principalmente entre os anos de 1995 e 2000, e fez da sua capital, Recife (e sua região metropolitana), a mais violenta do país, em alguns anos do período. A politica de estado mínimo, pela escassez de agentes públicos de segurança, contribuiu para a proliferação de arrastões nas ruas da cidade, estupros em coletivos e assassinatos, em que o assassino saía andando depois de cometer o crime com aparente tranquilidade, um vácuo de atuação do estado no qual foi instaurada uma grande onda de insegurança, de violência e homicídios no Brasil.

Palavras-chave: Estado; Segurança; Pública; Privada.

Abstract: The public safety paradigms derive from the types of policies associated to models of state. In the nineties, in Brazil, the state reform to managerial, or minimal, state was in the agenda. It was characterized by the decreased role of the state as supplier of public services, giving way to private initiatives and the market forces. It was not different with public safety. They tried to increase the efficiency of military police sectors through a reorganization, reordering and technical apparatus of these institutions. But the consequence was a stagnation in the supply of public safety agents to streets and public spaces as compared to the progressive increase in population. Along with this stagnation, the increase in supply of these services by the 
private security sector could also be seen, though not to those who could not afford it. To those who could not afford it, there remained the clandestine private security, in poor neighborhoods. This security policy template hit Pernambuco especially between 1995 and 2000, making its capital, Recife (and metropolitan area) the most violent in the country, in some years within that period. The minimal state policy through the lack of public safety agents contributed to the proliferation of mass lootings, public transit rapes and murders where the assassin calmly walked away after having committed the crime with ease, a vacuum of state action in which a great wave of insecurity, violence and homicides was established in Brazil.

Keywords: State; Security; Public; Private.

\section{Introdução}

Política de segurança pública é um tema bastante dinâmico. Durante certo período muitos críticos do estado apontavam as forças policiais como os braços repressores e mantenedores da ordem de classes ou do estado de coisas, e ainda não deixou de ser quando se trata de movimentações de cunho político e social. Contudo, hoje, de maneira antitética, - como neste trabalho - as forças policiais nas ruas passaram a ser agentes públicos de fundamental importância para assegurar a ordem pública relacionada à proteção da vida dos cidadãos, e são apontadas por alguns observadores e/ou teóricos sociais como agentes importantes para tal. Não é mais de exclusividade dos problemas econômicos, e sua resolução, a causa principal ou o apaziguar da onda de insegurança e violência pela qual passou e ainda passa, em certa medida, os brasileiros.

Levando em conta o aspecto dinâmico das Políticas de Segurança Pública ou de Segurança Pública este trabalho tem como objetivo principal analisar e apontar que uma determinada política de estado pode também contribuir para o aumento da violência e, por conseguinte do número de homicídios. Afirmando que esta política é e/ou foi a do estado mínimo e/ou gerencial. Embora não queira dizer que ela seja montada ou organizada intencionalmente como meio para este fim. Mas, como consequência, reflexo ou da estrutura desta.

Em forma de análise geral tentar-se-á, neste trabalho, trazer de volta o cenário da década de 1990, sobretudo, os anos que vão de 1995 até 2000 em Pernambuco, sua capital e região metropolitana. Período em que os indicadores de homicídios começaram a crescer progressivamente, tanto no país quanto no estado pernambucano. Recife neste mesmo período passou a figurar como uma das cidades mais violentas, e em alguns anos, como a cidade mais violenta do país (SAPORI, 2007).
No mesmo período, naquele mesmo decênio o estado brasileiro passou por uma por uma reestruturação, principalmente a partir de 1994, quando foi posta em curso a reforma para um estado mínimo que culminaria com a reforma gerencial do então presidente Fernando Henrique Cardoso e o seu ministro da reforma do estado Luiz Carlos Bresser-Pereira (BRESSER-PEREIRA; SPINK, 2005).

Um tipo de estado que se encolhia e tinha como principal diretiva a de deixar a cargo das forças e das iniciativas privadas do mercado a prestação de muitos serviços públicos (MORAES, 2002). Não diferente disto, a segurança pública também foi atingida por estas diretrizes. Ao mesmo tempo em que se via o crescimento dos números reais dos agentes e serviços de segurança privada, a quantidade policiais militares nas ruas estacionava e tendia a ser fortemente deficitária proporcionalmente a quantidade de pessoas.

Assim, em virtude desta política de segurança pública um vácuo de atuação do estado ou zona escura, de segurança pública, foi criado nas ruas. Sem o estado quem podia pagar por serviços e recursos de segurança privada detinham condições, mesmo que sob a onda de violência e homicídios, de relativamente protegerem-se. Enquanto, quem não dispunha deste recurso, ficou efetivamente a ver a onda criminosa passar bem perto e ser atingido de maneira mais veemente (LIMA et al., 2005). Inclusive a mercê de grupos privados de segurança clandestina que forneciam mais insegurança que insegurança.

O início do período foi escolhido por ter antecedido 1996 ano cuja taxa de homicídios registrada em Recife foi a maior entre as capitais brasileiras (SAPORI, 2007). Por isto, a capital de Pernambuco é sempre a protagonista dos dados, e representante de estado. Além disso, em alguns casos inicia-se o período de análise em 1995, por ter como objetivo apontar possíveis fatores antecedentes, que poderiam contribuir para aquele número. 
Mas, analisar este período apresentou dificuldades relacionadas à obtenção de dados. Durante o período, embora tivesse sido uma das bandeiras do governo federal modernizar as polícias, os dados não foram informatizados nem controlados. Dois exemplos importantes puderam ser vistos quando foram procuradas duas instituições responsáveis por segurança pública, embora com competência e objetivos de atuação diferentes, para apresentação de dados: A guarda Municipal do Recife e a Polícia Federal (DELESPE). A primeira não dispunha nem de registro manual ou fichas da quantidade de agentes da guarda no período solicitado. Foi fornecida uma quantidade aproximada verbalmente com base na contração do último concurso realizado. A segunda dispunha de dados feitos manualmente em livros de registros. Informatização de dados das duas instituições só com os registrados a partir de 2003. Portanto, para os dados da década de 1990 tem-se, em forma de manuscritos ou sem dados registrados, apenas um número aproximado, baseado em ideias aproximadas.

Em virtude destas dificuldades, para os dados relacionados a Policia Militar de Pernambuco no que diz respeito ao quantitativo e efetivo de homens ou agentes desta instituição de Segurança foi utilizada a quantidade máxima de policiais militares permitida e/ou definida por lei. E que mesmo assim mostrou-se proporcionalmente numa escala que tendeu a decrescer relacionada à quantidade de cidadãos aos quais estes agentes deveriam fornecer segurança. A polícia militar foi escolhida para ser o ator examinado por causa da sua importância no policiamento ostensivo diuturno nas ruas.

Além da periodização e suas dificuldades, este trabalho tem outra característica: a de generalização. Por ser uma análise geral e por utilizar um período até certo ponto longo, sem dúvida que muitas lacunas serão encontradas. Por problemas relacionados aos dados foram utilizados, além de artigos que fazem análise do período, também foram utilizadas matérias de jornais da época que mostram, no cotidiano, fatos relacionados ao problema do fornecimento de segurança pública pelo estado aos cidadãos em Pernambuco (Recife e RMR), sempre ligados ao tema da política de estado mínimo.

Portanto, tenta-se analisar e apontar que uma política ou diretriz política nacional sobre as bases de um modelo ou tipo de estado mínimo pode, além de fornecer estruturas deficitárias de segurança pública,contribuir como fator para a instauração de um cenário insegurança e altas taxas de homicídios.

\section{Política nacional e segurança: $1995-2000$}

As Políticas de Segurança Pública variam de acordo com os tipos de Estados. Partindo desta premissa pode-se verificar que o paradigma de segurança pública adotado para a década de 1990, após a promulgação da constituição de 1988 (BRASIL, 1988), dissociava os problemas sociais dos problemas do fornecimento de uma ordem pública segura (SAPORI, 2007).

Segundo dados publicados em um estudo realizado por Cerqueira et al. (2007), tomados como base números absolutos ou taxas, os homicídios no Brasil vêm crescendo desde 1980 de maneira alarmante. Poder-se-ia apontar de maneira simples baseada em observações de bases empíricas, porém não menos importante, alguns fatores favorecedores para este acréscimo. Por exemplo, a diminuição da presença do Estado brasileiro nas ruas cristalizado como elemento ou ator de contenção social, com o arrefecimento do regime de exceção, e o aumento da população no território nacional. Contudo, se uma observação política mais acurada for lançada sobre os dados apresentados no estudo de Cerqueira, aliado a estas duas observações simples, pode-se perceber que nem o aumento da população nem a diminuição da presença do Estado brasileiro como fator de segurança e de repressão social foram acompanhados com a devida atenção e cuidados pelo regime democrático, com as garantias e práticas efetivamente constitucionais, pelas políticas e políticos brasileiros das décadas de 1980 e 1990.

Um estudo de Moema Dutra Freire (2009) leva em consideração o ambiente histórico da formulação das políticas de segurança e o modelo adotado naquele período: Segurança Pública, entre a constituição de 1988 e o ano 2003. A autora nos fornece elementos importantes para a percepção do papel do Estado no Brasil, do período, como fornecedor de segurança e ordem pública. Ela assinala em seu estudo que mesmo com o texto da constituição de 1988 mencionando que a segurança é papel de todos, na prática há uma participação pequena dos indivíduos nesta. Além disto, o foco principal é a estratégia repressiva e está nas instituições policiais o papel predominante na implantação das políticas relacionadas à segurança.

Neste período, de redemocratização, o Brasil ainda estava sob o crepúsculo vespertino da bipolaridade e quase todas as reivindicações de cunho político-social adquiria uma aura, ou pairava sobres elas, a sombra de movimentos políticos revolucionários comunistas (ou marxistas - e alguns de fato o eram, enquanto outros procuravam mudanças sociais em vez de revolução política). Muitas daquelas reivindicações eram vistas com desconfiança e em alguns casos como elementos perniciosos e desestabilizadores da ordem pública. Ainda estava em vigor, derivada dos 
elementos imaginários do comunismo, a ideia de um inimigo interno (ZAVERUCHA, 2005). Por causa disto não é difícil perceber que o modelo de Segurança Pública adotado na década de 1990 excluía de suas formulações e implantações aspectos sociais como fatores importantes para a preservação da ordem pública.

Sincronicamente, além desta característica de afastamento das questões sociais na formulação das políticas de segurança pública, neste período também o estado brasileiro e os seus políticos concentraram seus esforços e ações políticas em controlar e encontrar uma saída para estabilizar a inflação e a economia nacional (RODRIGUES, 2010). Estes esforços culminaram com o plano Real de 1994 que conseguiu estabilizar a inflação. Este plano econômico e financeiro estaria sendo rebocado por tipo de estado implantado na Europa e na América do Norte (Estados Unidos) e transplantado para a América Latina já na década de 1980, segundo Cervo (2000), que deveria ter

[...] estrutura mínima, cuja função é garantir que a economia funcione, principalmente defendo o direito à propriedade, que envolve a proteção dos bens particulares, e assegurando que os contratos sejam cumpridos. (GRACIANO; MATSUDA; FERNANDES, 2009).

Esta estrutura mínima precisaria ser desenvolvida, estar bem estruturada e aparelhada para responder com eficiência e eficácia, apoiada no mercado, aos conflitos e às demandas geradas porproblemas políticos e econômicos. Enfim, a preocupação deste tipo de Estado implantado no Brasil na década de 1990 era ter órgãos e instituições modernizadas e bem estruturadas tecnologicamente, pois se acreditava que a tecnologia diminui gastos com a quantidade de agentes estatais.

Por conseguinte, esta ideia também atingiu a política de segurança pública. Criar-se-ia desta forma para ela uma estrutura assemelhada com o Panóptico de Bentham, todavia moderno e high-tech (FOUCAULT, 2004). Deste modo, em virtude desta característica apresentada e viabilizada no estado brasileiro, fomentada pelos agentes públicos e/ou políticos que fizeram parte do governo daquela segunda metade de década, as políticas de segurança pública formuladas foram focadas para as áreas na modernização estrutural, de órgãos e instituições, e isto ficou muito mais evidente na segunda metade da década de 1990 (SAPORI, 2007).

Os investimentos em segurança em sua maior parte foram endereçados à aquisição de novos equipamentos, como veículos e armas, às reformas físicas em instalações e em crimes especializados, em detrimento ao policiamento nas ruas e alguns espaços urbanos, além das fronteiras (ADORNO, 2003). O policiamento foi sendo preterido e tornou-se deficitário no controle destes espaços, como os fornecedores da ordem pública.

Para a prevenção da violência aquele modelo de política vigente direcionou enfaticamente a responsabilidade para o cidadão de se prevenir através de informações, de como ou quais comportamentos cada um deveria adotar para não ser acometido de atos violentos nas suas mais variadas expressões, entre eles o homicídio. Um estudo publicado de Peres (2007) mostra este comportamento do estado, pois segundo ela

[...] começam a surgir, nos jornais e revistas de grande circulação, guias e manuais que nos ensinam a evitar situações de violência. Cabe a nós usar esses conhecimentos $[\ldots]$

com

[...] adoção de medidas de cautela no trânsito, nas ruas, nos bares e, em última instância, a renúncia aos espaços públicos - ao menos nos horários de maior risco - traduzem a idéia de que "cada um de nós deve fazer a sua parte para se proteger [...]".

Portanto, caracteristicamente a política de segurança pública na década de 1990 foi formulada e implantada com base no paradigma do Estado mínimo. Daí a sua participação ou sua presença diminuída na regulação e intervenção preventiva nas ruas que ensejava, além disso, na sua diminuição de levar em conta o aspecto social para esta política (PERES, 2007).

A política de estado no período colocava no mercado a força motriz fornecedora de inclusão, de igualdade e de justiça para o campo social,como também o grande fornecedor eficiente de serviços para a sociedade (MORAES, 2002). Assim, o estado deixaria não por inação, mas por uma política estatal, uma lacuna, um vácuo que foi preenchido largamente pelo mercado. Esta política criou espaço para a instauração de colusão entre poder público na área de segurança e mercado (ZAVERUCHA, 2006). Assim, a própria diminuição de atuação na segurança pública também derivada da ideologia de atuação do mercado.

Por reflexo deste tipo de política houve o crescimento e expansão de empresas e tecnologias privadas de segurança pessoal e patrimonial, principalmente no período estudado, como apontam Zanetic (2009) na década de 1990 e Adorno (2003) na segunda metade daquela década.Também dados da Escola de Nacional de Administração Pública - ENAP (2005) demonstrameste crescimento, pois ataxa de agentes de segurança para cada 100.000 habitantes representava 43,5 para os agentes particulares, e de 22,9 para as forças policiais públicas.

Mas, este crescimento não foi apenas originado por contratações de profissionais ou empresas da 
área pela maior parte da população. Os agentes de segurança privada como prestadores de serviços dividir-se-iam: em formais e informais, registrados e clandestinos, resultado do próprio componente inerente aos vários seguimentos de mercados. $\mathrm{O}$ estudo de Zanetic (2009) indica que a disseminação deste setor tendeu principalmente para "edifícios empresariais e edifícios de instituições públicas", além "da pressão das companhias de seguros sobre seus clientes para a contratação de serviços especializados." Por estes aspectos, pode-se inferir que a segurança individual, empresarial e patrimonial cresceu, com a contratação de profissionais legalizados e regulamentados pelos segmentos econômicos mais privilegiados. Além disso, assinala também que aquele tipo de estado assume uma postura em fornecer segurança aos seus edifícios através dos serviços de segurança privados.

O estudo de Zanetic (2009) também apresenta o tipo de segurança privada não regularizada. Do qual se pode constatar que este tipo foi utilizado, muitas vezes por falta de opçãodos cidadãos, e executados por agentes de condutas ambíguas, muitas vezes, pelo segmento econômico menos privilegiado. Ele aponta

[...] categorias que fazem parte de uma zona obscura e não regularizada de atividades das mais diversificadas, mas que de fato compõem o vasto repertório dos serviços informais de segurança privada, como "celeireiro", "guariteiro", "olheiro", "ronda- noturno", "rondante", "vigiador" [...].

Em Pernambuco este tipo de serviço, de segurança clandestina, teve os agentesconhecidos, como a "turma do apito". Muitas vezes forneciam, comprovadamente, mais insegurança e medo do que segurança, tanto nas ruas e casas de bairros pobres, e das faixas econômicas menos privilegiadas. Por causa do comportamento suspeito e envolvimento em diversos delitos de muito destes agentes.

Enfim, a política do estado mínimo, colocada como ação de governo na década de 1990, sobretudo na segunda metade deste período, forneceu a estrutura de segurança pública baseada na repressão, na reforma e modernização das instituições policiaise na diminuição da sua atuação no fornecimento agentes de segurança pública, deixando de atuar preventivamente nas ruas. Por causa disso, passou para o cidadão a responsabilidade de prevenção da violência e dos homicídios. Assim, os que podiam financeiramente se resguardavam, enquanto os que não podiam sofriam a céu aberto os choques da insegurança e do medo - embora os dois seguimentos sofressem os impactos de uma segurança mínima, cabia ao cidadão buscar serviços de segurança no mercado, formal ou informal.

\section{Diretrizes, orçamento e consequências (1995-2000)}

Pernambuco também recebeu estruturalmente os reflexos do paradigma do estado mínimo da segunda metade da década de 1990, que incidiram sobre as políticas de segurança pública, embora a Constituição Federal de 1988 desse aos estados autonomia para formularem suas próprias políticas de segurança pública (FREIRE, 2009). No estado pernambucano houve sistematicamente a tentativa de implantação estrutural de segurança derivada da política estatal daquele período. Alguns itens não foram passíveis de realização, sobretudo no aspecto institucional e estrutural das polícias já explicados por Zaverucha (2006). Contudo, é possível perceber a implantação estrutural do modelo mínimo de estado em Pernambuco.

Houve a tentativa de modernização das policias como prioridade orçamentária. Não houve contratação ou readequação da quantidade de policiais, sobretudo de policiais militares ou militares-praças postos na estrutura de segurança como elementos de policiamento ostensivo e diuturno nas ruas, relacionada ao acompanhamento à quantidade e ao crescimento da população, característica base, do estado da reforma gerencial, não contratação ou diminuição de gasto com pessoal (MORAES, 2002). Por conseguinte, viu-se o aumento expressivo da quantidade de fornecimento de serviços de segurança privada por empresas através de agentes regulares e um crescimento expressivo do número de agentes legais e clandestinos.

\section{Diretrizes}

\section{Legislação e segurança pública}

Desde 1994, com as leis 11.096 e 11.100, as legislaturas de Pernambuco já acompanhavam as mudanças de um estado mínimo. A primeira lei apontava para a restauração e melhores condições dos estabelecimentos usados pelos órgãos de segurança pública no estado, como na Secretaria de Segurança Pública e de Justiça, além dos estabelecimentos da PMPE e ampliação, reequipamento e restauração das respectivas frotas de veículos. Depois, com a segunda lei, tinha-se a preocupação com a capacitação dos servidores, dentre outras áreas, da segurança pública; i.e.: havia em curso naquele período a reforma institucional, estrutural e organizacional do estado para que este se tornasse mais eficiente, com uma estrutura mínima. Continuada com a lei 11.561, de 1998, que prosseguia com o objetivo de dar expansão e melhoria no sistema de segurança enfatizando o reequipamento, reaparelhamento e capacitação do corpo de agentes de segurança pública no estado. 
Contiguamente a estas reformas infra e estruturais da segurança pública, a lei 11.467, de 1997, instituía a criação de um conselho, o de Defesa Social. Este órgão tinha como objetivo o assessoramento direto ao governador como entidade articuladora da integração entre vários setores, atores e instituições ligadas à segurança pública (e à justiça). E ainda também funcionaria como controlador e avaliador do orçamento dos órgãos e instituições atinentes à segurança pública. Um órgão de contornos gerenciais na segurança pública no estado.

Assim, Pernambuco acompanhou a mesma tendência da política de segurança pública de estado mínimo de maneira efetiva, localizada principalmente no campo institucional, organizacional e estrutural dos órgãos de segurança.

\section{Orçamento}

\section{Orçamento em segurança pública}

Ao contrário do que geralmente se espera, nem sempre déficits em determinadas áreas ou no fornecimento de serviços públicos pelo estado advêm de poucos investimentos ou redução de gastos. Em Pernambuco, no período entre 1995 e 2000 viu-se uma relação invertida entre gastos com segurança e aumento de agentes policiais (militares) contratados para policiar as ruas.

Entre 1995 e o ano 2000, quando o orçamento de segurança começou a ser direcionado à Secretaria de Defesa Social, o estado havia gasto um total de quase dois bilhões e meio de reais nesta área. Os gastos com segurança cresceram $128,54 \%$, passando de R\$ 240,1 milhão em 1995 para R\$ 548,7 milhões em 2000. Desta forma, pode-se constatar, como está demonstrado (a seguir) no Gráfico 1, que os gastos anuais do estado nesta área mais do que dobraram no período em questão.

Todavia, estes gastos não foram direcionados efetivamente para a ampliação do aparato operacional e de policiamento ostensivo nas ruas, pois, o orçamento do setor priorizou as reformas institucionais e estruturais dos órgãos da segurança. Portanto, não houve ausência de gastos, mas os seus direcionamentos obviamente estiveram ligados ao tipo de política de segurança de um estado mínimo (GRACIANO, MATSUDA; FERNANDES, 2009).

\section{Orçamento e Polícia Militar}

$\mathrm{O}$ orçamento de segurança em Pernambuco para a polícia militar também aumentou na mesma razão direta. Os gastos com a polícia militar cresceram mais de $140 \%$. Saíram de R $\$ 141.232 .800,00$ e chegaram $\mathrm{R} \$ 341.337 .700,00$ ao final do período. Embora tenha sofrido uma diminuição para o exercício de 1997. Como é possível ver no Gráfico 2, a seguir.
Além disso, a comparação do orçamento estadual entre os órgãos de segurança pública, visualizada no Gráfico 3 (a seguir), na qual estão a Secretaria da Segurança Pública, o Corpo de Bombeiro Militar de Pernambuco e a Polícia Militar de Pernambuco,

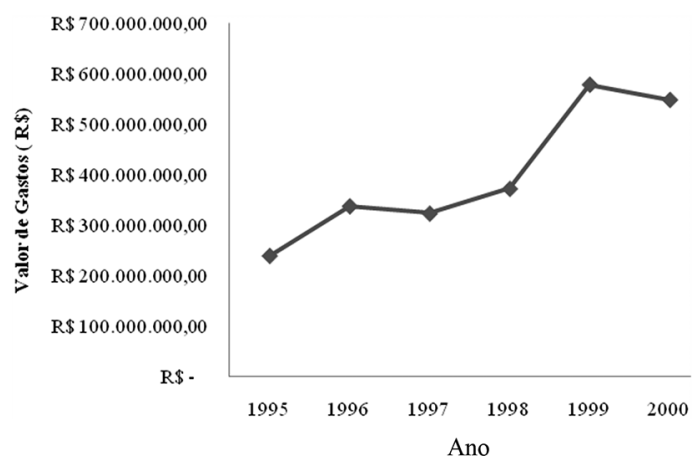

Gráfico 1. Gastos, com base no orçamento, de Segurança Pública em Pernambuco entre 1995 e 2000. Fonte: Base de dados LegisPE da Assembleia Legislativa de Pernambuco (PERNAMBUCO, 2010).

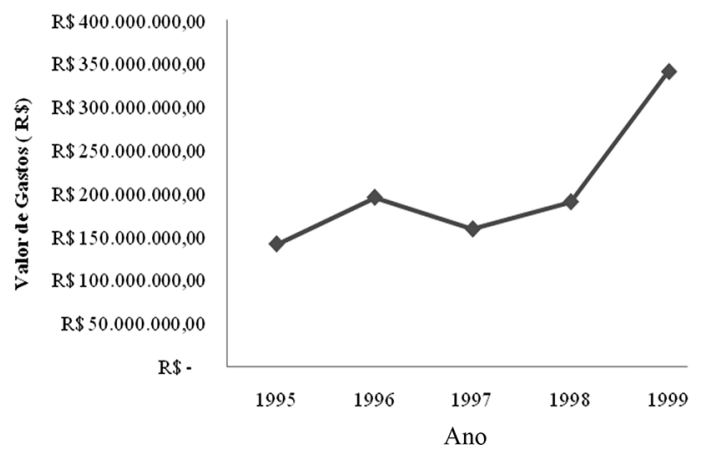

Gráfico 2. Gastos, com base no orçamento, da Polícia Militar de Pernambuco entre 1995 e 1999. Fonte: Base de dados LegisPE da Assembleia Legislativa de Pernambuco (PERNAMBUCO, 2010).

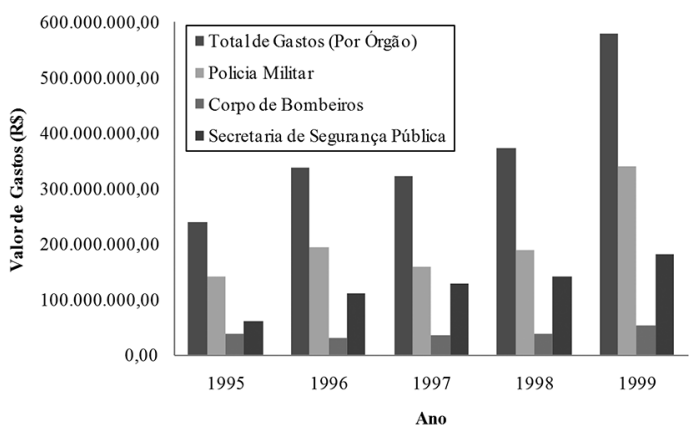

Gráfico 3. Comparação dos gastos, com base no orçamento,dos os órgãos de Segurança Pública de Pernambuco entre 1995 e 1999. Fonte: Base de dados LegisPE da Assembleia Legislativa de Pernambuco (PERNAMBUCO, 2010). 
resultou no maior direcionamento da maior parte dos gastos para este último órgão, sempre superior a $50 \%$. Excetuando-se ainda o mesmo exercício de 1997 quando acompanhou a queda do orçamento global da Secretaria de Segurança Pública.

Ou seja, a polícia militar, enquanto órgão da segurança pública, percebeu um aumento de cerca de $100 \%$ nos seus recursos, até o final do período estudado. Mas, estes gastos não ampliaram o númerode policiais militares a patrulharem as ruas.

\section{Consequências}

Com maior prioridade na reforma, modernização, reaparelhamento e reestruturação das instituições de segurança, o estado diminuiu os seus gastos públicos com pessoal para o fornecimento e prestação de serviços de segurança para o público (MORAES, 2002). Como consequência disto, o preenchimento da lacuna deixada pelo estado foi feito pelo setor privado, pelo mercado (MORAES, 2002). Isto contribuiu para aumentar a quantidade de agentes de segurança privada e para o aumento da segurança clandestina (informal ou não regularizada), como para preencher esta lacuna.

No estado pernambucano a polícia militar foi encolhendo na medida em que os anos foram passando e a população crescendo, embora a corporação tenha percebido um aumento considerável de mais de $100 \%$ no seu orçamento mesmo período.

\section{Polícia Militar: efetivo x população}

A quantidade máxima de agentes da polícia militar é definida por lei. E no período entre 1995 e 2000, mesmo com os índices já alarmantes de homicídios em Pernambuco, e na sua capital, não houve mudança estrutural para incrementar em quantidades de agentes as forças ostensivas de patrulhamento das ruas. Pelo contrário, a lei 11.323 de 1996 fixava o teto máximo da quantidade de policiais militares em todo o estado para 21.127, diminuindo a quantidade de PMs na estrutura da segurança pública, antes fixada em 23.338 pela lei 10.988 de 1993. Desta forma, em 1996, acompanhando a diretriz política nacional, o estado pernambucano diminuía a quantidade de pessoal de segurança.

À medida que os anos transcorreram na década de 1990, a populaçãono estado tendeu ao crescimento. No caso de Recife, entre 1995 e 2000, além da quantidade já existente, houve um acréscimo na população de aproximadamente $6 \%$, cerca de $80 \mathrm{mil}$ pessoas (BRASIL, 2010b). Contudo, mesmo com este crescimento a quantidade máxima de policiais permaneceu. Conseguintemente[sic] a taxa de policiais militares x população decresceu, demonstrada a seguir, no Gráfico 4. Pela taxa de policiais por cada grupo de 100 mil habitantes, constata-se uma queda abrupta de policiamento nas ruas, principalmente a partir de 1996.

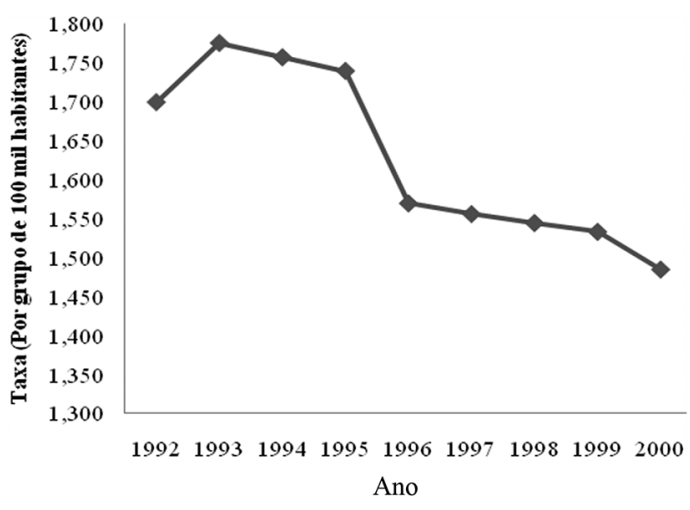

Gráfico 4. Taxa de Policiais Militares por grupo de 100 mil habitantes entre 1992 e 2000. Fonte: Base de dados LegisPE da Assembleia Legislativa de Pernambuco (PERNAMBUCO, 2010).

Assim, esta queda acentuada apontava para um cenário de vácuo de policiamento nas ruas, que criava desta forma uma zona bastante propensa para a atuação do mercado através de empresas privadas de segurança, como também a atuação de seguranças clandestinos.

\section{Segurança privada}

A estrutura do estado mínimo renunciava à contratação de novos agentes públicos de segurança ostensivo para as ruas, assim, o que se viu foi a entrada e o crescimento acentuado do setor privado no fornecimento de segurança. Em Pernambuco, segundo dados da Junta Comercial de Pernambuco - JUCEPE, entre 1994 e 2000 foram registradas 328 empresas de vigilância, segurança e transporte de valores.

Ao final deste mesmo período, segundo dados da Delegacia de Segurança Privada - DELESP da Polícia Federal em Pernambuco haviam sido contratados 19.327 profissionais de segurança privada no estado. Completando o número de 40.618 profissionais em segurança registrados ao final da década de 1990 cujo crescimento se deu principalmente na segunda metade daquela década. Ao comparar-se o número de seguranças privados com a quantidade de recifenses - grupos de 100 mil habitantes - tem-se um aumento progressivo, como é demonstrado no Gráfico 5 (a seguir), destes profissionais.

Houve, em Pernambuco, um aumento expressivo da presença das empresas de segurança privada no fornecimento de segurança para o cidadão, para os que podiam pagar é claro.

Os dados da ENAP (2005) apontam, como também o gráfico a seguir (Gráfico 6), que ao final da década de 1990 a relação entre segurança pública e privada era o dobro da taxa, com vantagem para esta última, e com base no número de habitantes no Brasil. 


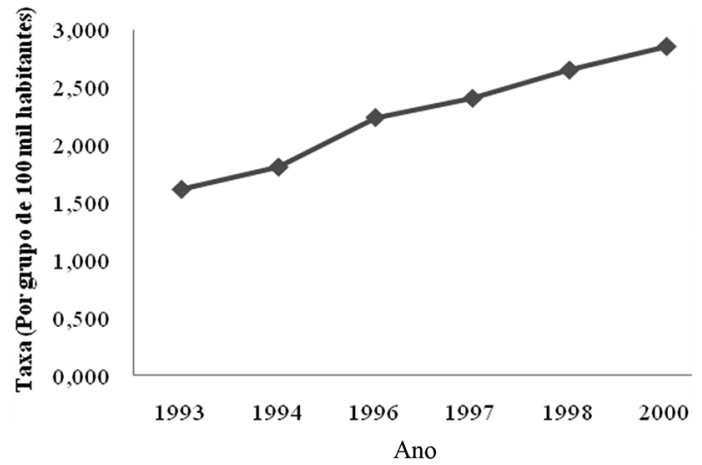

Gráfico 5. Taxa de Profissionais de Segurança Privada por grupo de 100 mil habitantes entre 1993 e 2000 . Fonte: Dados recebidos por anotações manuais, obtidos na Delegacia de Controle de Segurança Privada (DELESP-PE).

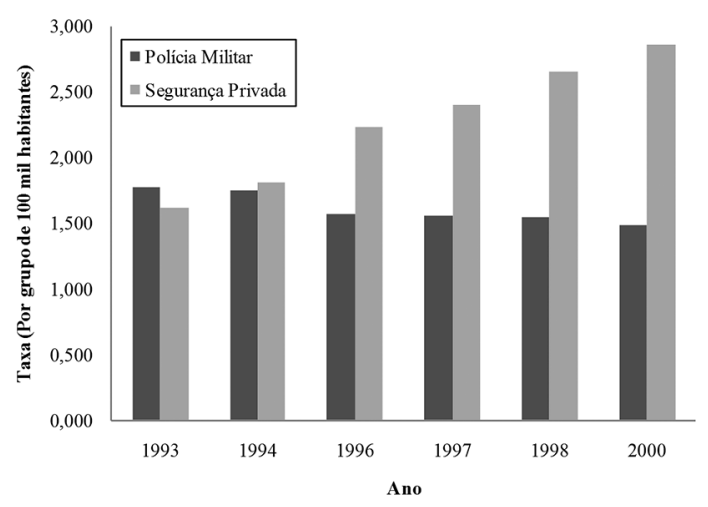

Gráfico 6. Comparação entre as taxas de Policiais Militares e Profissionais de Segurança Privada por grupo de 100 mil habitantes em Pernambuco entre 1993 e 2000. Fonte: Base de dados LegisPE da Assembleia Legislativa de Pernambuco.e dados recebidos por anotações manuais, obtidos na Delegacia de Controle de Segurança Privada (DELESP-PE) (PERNAMBUCO, 2010).

Em Pernambuco com base apenas na quantidade de habitantes da sua capital, ao final da mesma década, esta relação era a mesma para o policiamento efetivo das ruas, ou seja, de quase o dobro.

Portanto, ao transcurso da década de 1990 viu-se efetivamente a saída em partes do estado como fornecedor de segurança e o mercado se tornou um agente da política estatal também provedor deste tipo de serviço público.

\section{Segurança clandestina (Turma do apito)}

A diminuição do estado como fornecedor de segurança como bem público, além de ter suscitado a entrada robusta das empresas de segurança privada como fornecedoras de tal bem, para os que podiam pagar, também abriu espaço a uma modalidade de segurança privada, para os que não podiam pagar e muitas vezes não tinham escolha: a não regulamentada.

Esta modalidade pode receber várias denominações de acordo com a região (ZANETIC, 2009). Em Pernambuco estes agentes clandestinos de segurança passaram a ser conhecidos por: "a turma do apito". Por falta de fontes de dados para relatar o crescimento da participação destes agentes no cotidiano dos moradores pernambucanos, como fornecedores aparentes de segurança, não se pode mais aprofundar aqui neste estudo.

Contudo, pode-se afirmar que no vácuo deixado pela política de segurança do período, ou seja, sem policiamento ou uma quantidade adequada de policiais nas ruas este tipo de segurança foi oferecido de maneira compulsória ao mais largo e mais amplo seguimento da população: aos moradores dos bairros pobres. O que também contribuiu como componentes para a construção de uma ordem de insegurança pública geral uma vez que estes pseudo-seguranças muitas vezes impunham mais desconfianças aos moradores dos bairros pernambucanos, pois não estiveram envolvidos em muitas ocasiões em crimes e em eventos de violências.

\section{Homicídios em Recife, estrutura mínima do estado, mínimo de Polícia Militar e impactos na vida dos cidadãos pernambucanos}

Os impactos das diretrizes de um estado mínimo podem ser percebidos em alguns aspectos em Pernambuco, relacionados à segurança pública. A diminuição ou não atuação, em uma parte maior na segurança pública, propiciou o aparecimento de zonas escuras não habitadas por estes serviços estatais. Em decorrência disto com o fornecimento de segurança diminuído como serviços de natureza estatal ao cidadão,viu-se a partir dessas zonas escuras, nas ruas, instaurada uma onda crescente e alarmante de violência, insegurança e de homicídios.

Cabendo então ações políticas emergenciais do governo do estado à responsabilidade e competências de preencher as lacunas deixadas por esta estrutura. Os cidadãos do Recife e a sua Região Metropolitana (RMR) viram no seu cotidiano estes impactos.

É certo, e prudente, que se leve em consideraçãoneste estudo o que o professor Elimar Pinheiro do Nascimento (2002) preferiu apontar como sendo alguns aspectos, fatores ou elementos potenciais do aumento da violência, e não causas. Contudo, partindo-se da premissa de que o Estado e suas políticas se tornaram ao longo da história moderna o principal agente no fornecimento de segurança pública para os seus cidadãos, além de deter o monopólio da violência, pode-se constatar que o aumento da violência, da insegurança e dos 
homicídios também pode ter como causa direta uma inação política, como também uma ação mal sucedida derivada do estado (SAPORI, 2007).

\section{Homicídios em Recife}

Durante a década de 1990, e principalmente na segunda metade, Recife a capital do estado figurou como uma das protagonistas e líderes em maiores taxas de homicídios entre as capitais brasileiras. Entre 1991 e 2000 a taxa de homicídios na capital pernambucana cresceu cerca de $24 \%$, segundo dados do Ministério da Saúde (BRASIL, 2010a). Sendo que o principal crescimento do período se deu entre os anos de 1996 e 2000 registrando uma taxa maior que $26 \%$. Diferentemente do quinquênio anterior que havia registrado um decréscimo de cerca de $6 \%$ na taxa de homicídios da cidade.

Quanto ao número de óbitos por homicídios registrados na década tem-se um total de 7.902 mortes por esta causa. Sendo 3.210 registradas de 1991 até 1995. E 4.692 entre 1996 e 2000. Além destes números destacados, vale salientar que quase um quarto dos homicídios registrados entre 1996 e 2000 aconteceu em 1998 quando o governo do estado, em resposta, empreendeu uma ação política emergencial de segurança para arrefecer a onda de crimes e violência no estado, como é possível ver e constatar, a seguir, através do Gráfico 7.

\section{Estrutura mínima do estado e mínimo de polícia militar}

Em 27 de agosto de 1998 o Jornal do Commercio tinha como a principal manchete no seu caderno de cidades: "Policiais, enfim, chegam às ruas da RMR" (POLICIAIS..., 1998). Denotando e registrando na prática, no cotidiano o vácuo ou a zona escura deixada

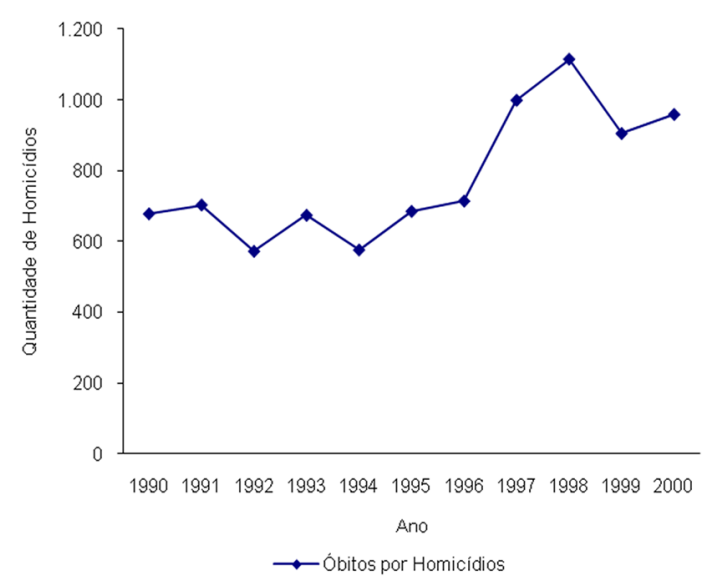

Gráfico 7. Quantidade de óbitos por homicídios em Recife entre 1990 e 2000. Fonte: Base de dados DATASUS do Ministério da Saúde (BRASIL, 2010b). pela ação diretiva de uma política de segurança pública, sobre as bases de um estado como menor quantidade de agentes públicos, no fornecimento de serviço inerente a segurança.

Esta mesma matéria registra de maneira emblemática através de Foto 1 (a seguir) a reação de expressiva surpresa da população relacionada à presença dos policiais no policiamento das ruas, fazendo o seguinte comentário: "Novidades: desacostumado com a presença de policiais na rua, recifense ficou surpreso com ação da PM." Além disso, o depoimento da doméstica Marli dos Santos, na mesma matéria, corroborava isto ao afirmar em parte do seu depoimento: "e ninguém via a polícia na rua."

A ação contava com efetivo em folga. Ela dispunha da presença de 700 policiais na operação (350 por dia - dispostos em duplas) espalhados em seis bairros do Recife cujo objetivo era mostrar a presença da PM na rua. Nesta ação havia o aumento do efetivo ostensivo de policiamento das ruas utilizando a reconfiguração das escalas de serviços, e não um acréscimo na quantidade real, total ou permanente de policiais militares. Ou seja, utilizava o efetivo de folga para um crescimento artificial do efetivo no policiamento.

O objetivo da operação foi claro: mostrar a presença da PM nas ruas, algo que as evidências mostram efetivamente não estava acontecendo. Foram colocados mais $350 \mathrm{PM}$ nas ruas naquele dia, pode-se constatar o espaço deixado pelo estado em atuar no fornecimento de segurança pública através do fornecimento de policiamento à população.

Aquela ação do estado pernambucano como meio de conter a violência e a onda crescente de homicídios mostram através dos números (ver Gráfico 7) evidenciavam que a ação dos governos pode efetivamente contribuir para refrear ou diminuir atitudes criminosas e homicidas ao aumentar a quantidade de efetivo de policiais militares nas ruas, mesmo que artificialmente como o caso apresentado.

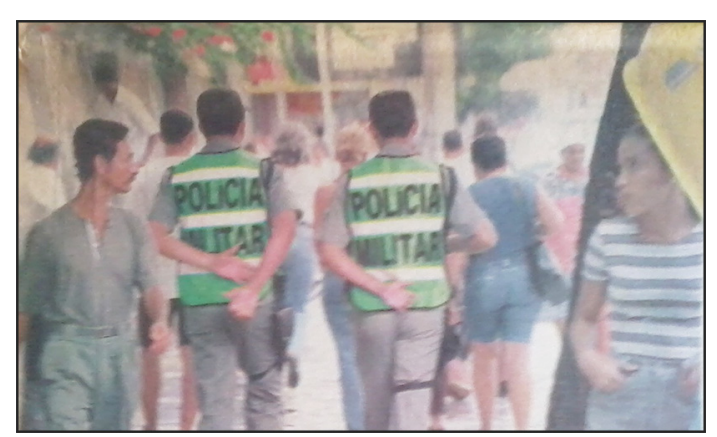

Foto 1. Surpresa dos cidadãos ao verem os policiais chegarem às ruas. Fonte: POLICIAIS... (1998). 


\section{Impactos na vida dos cidadãos pernambucanos}

Embora uma política de estado incidida diretamente sobre todos os incluídos dentro das suas linhas territoriais a maneira como os cidadãos se adéquam a ela variam de diversas formas. Isto está indubitavelmente entrelaçado e deriva a que grupo social, político e/ou econômico do qual façam parte. $\mathrm{O}$ minimalismo do estado no fornecimento de segurança ostensiva nas ruas, e o vácuo ou zona escura criada por esta política, atingiu tanto o seguimento não abastado economicamente quanto o outro lado (o abastado) do povo pernambucano.

O lado abastado das pessoas em Pernambuco refugiou-se atrás das suas estruturas e possibilidades de classes médias e altas. Naquele período, empresários substituíam os seus carros simples por blindados. E já havia em curso a nova tendência estrutural da arquitetura urbana a desenhar os espaços das cidades, os condomínios fechados. Quando por força da insegurança estes mesmos grupos passaram a estruturar às suas moradias com muros altos e guaritas com vigilância particular contratada e regulamentada permanente.

Além disso, os jovens deste mesmo seguimento socioeconômico passaram a adotar condutas relacionadas às suas próprias proteções, como registrou o Jornal do Commercio de 2 de agosto de 1998 (CLASSE..., 1998; JOVENS..., 1998). Como parte da transferência aos cidadãos da responsabilidade com asua seguranças nas vias pública. Andavam em grupo e ainda dispunha de equipamentos eletrônicos, como o celular, para comunicação de emergências, já os menos abastados enfrentaram em terreno descampado o déficit de seguranças nas ruas.

Dentro da zona escura. Sem policiamento nas ruas andar nos coletivos não era tarefa segura. Mulheres eram estupradas dentro destes (no ano de 1998 até o final do mês agosto quatro casos já tinham sido registrados), registro feito pelo Jornal do Commercio em 14 de agosto de 1998 cujo destaque foi a ocorrência de uma balconista estuprada em um coletivo (BALCONISTA..., 1998). Além disso, grupos de marginais (ou criminosos) intitulados de "galeras", um grupo criminoso formado principalmente dos jovens, proliferaram-se (LIMA et al., 2005). Causando desordem e medo geral por meio de ações nas ruas que passaram a serem conhecidas como "arrastões" que espalhavam medo e pânico nos moradores de Recife e da sua região RMR. Estes atos marginais que além de deixar pessoas sem seus objetos (ou pertences) resultavam em invasões de casas para praticar furtos e era capaz de ferir e/ou espancar e até matar pessoas. Como foi o caso do bairro de Caetés III, município de Abreu e Lima (RMR de Recife), visto na matéria do Jornal do Commercio de 25 de agosto de 1998 na qual mostrava situação das famílias daquele bairro, acuadas pelo medo (FAMÍLIAS..., 1998).

No dia 22 de agosto de 1998 este grupo impôs uma onda de medo a aquele bairro. Com consequências fatais a alguns daqueles moradores. Nesta ação os criminosos mataram três pessoas, feriram duas e roubaram quatro casas em uma mesma rua. Os moradores mortos: dois tentando impedir o roubo/invasão da sua casa e outro por tentar fugir depois de ser bastante espancado.

Vale salientar que a ação ocorreu sem qualquer intercurso imediato de atuação da polícia militar (ou qualquer outra). Constata-se neste evento que os cidadãos ficaram encarregados da sua própria defesa e/ou segurança. Não havia posto policia instalado no bairro, houve uma ação policial no dia seguinte. Ou seja, uma ação retardatária, não houve repressão nem prevenção.

Os moradores denunciavam que eram roubados diariamente. Estavam entregues a si mesmos, ou se utilizando da via religiosa para evocar proteção diziam: "Nós estamos entregues a Deus." E afirmavam do seu plano social e econômico: "polícia a gente só vê de longe."

Em função desta ausência de segurança dos agentes regulares/públicos como agentes de seguranças, principalmente dos subúrbios e bairros pobres surgiram grupos clandestinos conhecidos como "turma do apito". Grupo que muitas vezes estiveram envolvidos em comportamentos suspeitos e não transmitiam geralmente confiança e segurança aos moradores daquelas localidades (KOURY, 2004). Pelo contrário, eram às vezes suspeitos de cometerem furtos e assassinatos.

Assim, neste cenário as ruas se tonaram um espaço inseguro. Com uma presença menor do estado e uma política de segurança pública não fornecedora de policiamento suficiente e permanente para as vias públicas, estas passaram a ser um local onde as facilidades de práticas de crimes se tornaram frouxas. Desta forma, a população pernambucana passou a viver envolvido sob uma onda de insegurança e medo, cujo cume foi expresso nos altos números de homicídios apresentados na segunda metade da década de 1990.

\section{Considerações finais}

Ao fazer esta breve análise baseada na estrutura apresentada pelo modelo e/ou tipo de estado que esteve vigente no Brasil na segunda metade da década de 1990 pode-se considerar que ele como fator também esteve ligado ao aumento da insegurança, da violência e dos homicídios no Brasil, no período. Todavia, como já foi afirmado, não se pode dizer que este tipo de política estivesse montado diretamente para isto, mas, que se tornou parte da consequência ou resultado de 
um plano governamental, que obteve sucesso parcial em algumas áreas como na economia, mas que na segurança pública se constatou desastroso para o cidadão em Pernambuco, caso analisado.

No seminário realizado em 1996, em Brasília, que formalizava a reforma gerencial do estado brasileiro já se tinha a ideia não muito certa sobre as consequências da reforma e apontavam-se dúvidas sobre as fronteiras entre estado e mercado no fornecimento de bens públicos aos cidadãos. As dúvidas para o caso da segurança pública foram substituídas, segundo os resultados dos números e cenário apresentado neste trabalho, pela política de estacionar a quantidade de policiais nas ruas. E dando mais espaço ao setor privado para atuar na área de segurança. Quanto à incerteza sobre as consequências da reforma, em certa medida hoje se pode aferi-la - embora de maneira limitada e recortada por esta observação, pelo menos na área de segurança pública. O que se viu foi o aumento da violência, dos homicídios e da insegurança pública geral no Brasil.

Dizer que a segurança pública também foi privatizada, como muitas outras atividades e serviços antes fornecidos pelo estado também o foram, seria tomar emprestado um discurso ideológico que não cabe aqui no momento. Mas, ela foi reordenada ou reestruturada para organizar-se no plano institucional e em seus órgãos, para ser diminuída ou estagnada para a proteção dos cidadãos nas ruas, não se restam dúvidas.

Houve política de segurança pública sim, para e pelo estado, não para o cidadão. Continuou-se a política de proteção do estado pelo estado e não das pessoas pelo estado. Como se o estado estivesse ameaçado por uma ordem diferente e clandestina que pudesse a qualquer momento atentar contra ele.

Um erro político e/ou de política cujas consequências públicas para as pessoas foram e ainda são irrecuperáveis. Foi assim constado que a política do estado mínimo considerada, na década de 1990, como a grande transformadora do estado brasileiro em um estado eficiente, passou a ser uma ação política programática, por extensão à segurança pública ineficiente cujos resultados foram ineficazes e altamente desastrosos.

Este trabalho não sairia do caminho de acompanhar a prudência dos vários autores- que foram bases para este -, a de acreditar que não há apenas uma causa para a grande onda de insegurança, violência e de homicídios, mas fatores. Sendo assim, considera a política de estado mínimo um dos fatores que contribuíram para o crescimento desta ordem insegura e quase sem controle e que a certa altura, na segunda metade da década de 1990 parecia efetivamente não ter mais freio.

\section{Referências}

ADORNO, S. Lei e ordem no segundo governo FHC. São Paulo: Tempo Social - USP, 2003.

BALCONISTA é estuprada em ônibus. Jornal do Commercio, 14 ago. 1998.

BRASIL. Constituição (1988). Constituição da República Federativa do Brasil. Brasília, DF: Palácio do Planalto, 1988. Disponível em: $<$ https://www.planalto.gov.br/ ccivil_03/Constituicao/Constitui\%E7ao_Compilado. $\mathrm{htm}>$. Acesso em: 2 jun. 2010.

BRASIL. Ministério da Saúde. Datasus. Óbitos por causas externas - Pernambuco. Brasília, 2010a. Disponível em http://tabnet.datasus.gov.br/cgi/deftohtm.exe?sim/ cnv/ext10PE.def. Acesso em: 10 jun. 2010

BRASIL. Ministério da Saúde. Datasus. População residente - Pernambuco. Brasília, 2010b. Disponível em $<$ http://tabnet.datasus.gov.br/cgi/deftohtm.exe?ibge/ cnv/popPE.def $>$. Acesso em: 20 jun. 2010.

BRESSER-PEREIRA, L. C.; SPINK, P. (Org.). A Reforma do Estado e Administração Pública Gerencial. Rio de Janeiro: Editora FGV, 2005.

CERQUEIRA, D.; LOBÃO, W.; CARVALHO, A. O jogo dos sete mitos e a miséria da segurança pública no Brasil. In: BATITUCCI, E. C.; CRUZ, M. V. G. (Orgs.). Homicídios no Brasil. Rio de Janeiro: Editora FGV, 2007.

CERVO, L. A. Sob o signo do neoliberalismo: as relações internacionais da América Latina. Revista Brasileira de Política Internacional, v. 43, n. 2, p. 5-27, 2000.

CLASSE média acuada pela violência. Jornal do Commercio, 2 ago. 1998.

ESCOLA NACIONAL DE ADMINISTRAÇÃO PÚBLICA - ENAP. Definição e Interpretação dos Indicadores. Brasilia, 2005. Disponível em: <http://www.enap. gov.br/downloads/ec43ea4fIndicadoressociais.pdf $>$. Acesso em: 30 jul. 2009.

FAMÍLIAS de Caetés acuadas pelo medo. Jornal do Commercio, 25 ago. 1998.

FOUCAULT, M. Vigiar e Punir. Rio de Janeiro: Vozes, 2004.

FREIRE, M. D. Paradigmas de Segurança no Brasil: da ditadura aos nossos dias. Revista Brasileira de Segurança Pública, ano 3, n. 5, p. 100-114, 2009.

GRACIANO, M.; MATSUDA, F.; FERNANDES, F. C. Afinal, o que é Segurança Pública? São Paulo: Global, 2009.

JOVENS saem em grupo e com o celular à mão. Jornal do Commercio, 2 ago. 1998.

KOURY, M. G. P. Cultura do Medo e Juventude no Brasil atual. Revista Brasileira de Sociologia da Emoção, v. 3, n. 8, p. 199-218, 2004.

LIMA, M. L. C. et al. Análise espacial dos determinantes socioeconômicos dos homicídios no Estado de Pernambuco. Revista de Saude Publica, v. 39, n. 2, 
p. 176-182, 2005. http://dx.doi.org/10.1590/S003489102005000200006.

MORAES, R. C. Reformas neoliberais e Políticas Públicas: hegemonia ideológica e redefinição das relações Estado-Sociedade. Educucação \& Sociedade, v. 23, n. 80, p. 13-24, 2002.

NASCIMENTO, E. P. Violência urbana: o eixo da conjuntura social brasileira no final do século XX. In: ZAVERUCHA, J.; BARROS, M. R. N. (Orgs.). Seminário Internacional Políticas de Segurança Pública: dimensão da formação e impacto social. Recife: Editora Massangana, 2002.

PERES, M. F. T. Homicídios, risco e vulnerabilidade: para uma discussão da dinâmica da vitimização por homicídios. In: BATITUCCI, E. C.; CRUZ, M. V. G. (Orgs.). Homicídios no Brasil. Rio de Janeiro: Editora FGV, 2007.

PERNAMBUCO. Assembleia Legislativa. Bem-vindos ao Alepe Legis. Recife, 2010. Disponível em: <http:// legis.alepe.pe.gov.br/>. Acesso em 10 jul. 2010.
POLICIAIS, enfim, chegam às ruas da RMR. Jornal do Commercio, 27 ago. 1998.

RODRIGUES, M. M. A. Políticas Públicas. São Paulo: Publifolha, 2010.

SAPORI, L. F. Segurança Pública no Brasil: desafios e perspectivas. Rio de Janeiro: Editora FGV, 2007.

ZANETIC, A. Segurança Privada: características do setor e impacto sobre o policiamento. Revista Brasileira de Segurança Pública, v. 3, n. 4, p. 134-151, 2009.

ZAVERUCHA, J. FCH, Forças Armadas e Policia: entre o autoritarismo e a democracia (1999-2002). Rio de Janeiro: Record, 2005.

ZAVERUCHA, J. Policia Civil de Pernambuco: o desafio da reforma. Recife: Editora Universitária da UFPE, 2006. 